\title{
Correction to: Dot tracking methodology for background-oriented schlieren (BOS)
}

\author{
Lalit K. Rajendran ${ }^{1}$. Sally P. M. Bane ${ }^{1} \cdot$ Pavlos P. Vlachos $^{2}$
}

Published online: 5 August 2020

C Springer-Verlag GmbH Germany, part of Springer Nature 2020

Correction to: Experiments in Fluids (2019) 60:162 https://doi.org/10.1007/s00348-019-2793-3

In the version of the article originally published, a source of funding was missing under the Acknowledgment section.

The corrected Acknowledgment section should include the following statement:

This work was also supported by NSF 1706474.

Publisher's Note Springer Nature remains neutral with regard tojurisdictional claims in published maps and institutional affiliations.

The original article can be found online at https://doi.org/10.1007/ s00348-019-2793-3.

Pavlos P. Vlachos

pvlachos@purdue.edu

1 School of Aeronautics and Astronautics, Purdue University, West Lafayette, USA

2 School of Mechanical Engineering, Purdue University, West Lafayette, USA 